\title{
Increased numbers of small circulating endothelial cells in renal cell cancer patients treated with sunitinib
}

\author{
Laura Vroling • Astrid A. M. van der Veldt • Richard R. de Haas • \\ John B. A. G. Haanen - Gerrit Jan Schuurhuis · Dirk J. Kuik · \\ Hester van Cruijsen · Henk M. W. Verheul · Alfons J. M. van den Eertwegh • \\ Klaas Hoekman · Epie Boven · Victor W. M. van Hinsbergh • \\ Henk J. Broxterman
}

Received: 17 November 2008 / Accepted: 26 January 2009/Published online: 11 February 2009

(C) The Author(s) 2009. This article is published with open access at Springerlink.com

\begin{abstract}
Mature circulating endothelial cell (CEC) as well as endothelial progenitor populations may reflect the activity of anti-angiogenic agents on tumor neovasculature or even constitute a target for anti-angiogenic therapy. We investigated the behavior of CECs in parallel with hematopoietic progenitor cells (HPCs) in the blood of renal cell cancer patients during sunitinib treatment. We analyzed the kinetics of a specific population of small VEGFR2expressing CECs $\left(\mathrm{CD} 45^{\text {neg }} / \mathrm{CD} 34^{\text {bright }}\right)$, HPCs $\left(\mathrm{CD} 45^{\mathrm{dim}} /\right.$
\end{abstract}

Laura Vroling and Astrid A. M. van der Veldt contributed equally to this study.

L. Vroling - A. A. M. van der Veldt · R. R. de Haas .

H. van Cruijsen - H. M. W. Verheul .

A. J. M. van den Eertwegh - K. Hoekman · E. Boven ·

H. J. Broxterman $(\bowtie)$

Department of Medical Oncology, VU University Medical

Center, CCA 2-54, De Boelelaan 1117, 1081 HV Amsterdam,

The Netherlands

e-mail: H.Broxterman@vumc.nl

L. Vroling

e-mail: 1.vroling@vumc.nl

J. B. A. G. Haanen

Department of Medical Oncology, The Netherlands Cancer Institute, Antoni van Leeuwenhoek Hospital, Amsterdam, The Netherlands

G. J. Schuurhuis

Department of Hematology, VU University Medical Center, Amsterdam, The Netherlands

D. J. Kuik

Department of Clinical Epidemiology and Biostatistics, VU University Medical Center, Amsterdam, The Netherlands

V. W. M. van Hinsbergh

Department of Physiology, VU University Medical Center, Amsterdam, The Netherlands
CD34 ${ }^{\text {bright }}$ ), and monocytes in the blood of 24 renal cell cancer (RCC) patients receiving $50 \mathrm{mg} /$ day of the multitargeted VEGF inhibitor sunitinib, on a 4-week-on/2-weekoff schedule. Blood was taken before treatment (C1D1), on C1D14, C1D28, and on C2D1 before the start of cycle 2. Also plasma VEGF and erythropoietin (EPO) were determined. Remarkably, while CD34 $4^{\text {bright }}$ HPCs and monocytes decreased during treatment, CD34 $4^{\text {bright }}$ CECs increased from 69 cells $/ \mathrm{ml}$ (C1D1) to 180 cells $/ \mathrm{ml}$ (C1D14; $P=0.001)$ and remained high on C1D28. All cell populations recovered to near pre-treatment levels on C2D1. Plasma VEGF and EPO levels were increased on C1D14 and partly normalized to pre-treatment levels on C2D1. In conclusion, opposite kinetics of two circulating CD34 ${ }^{\text {bright }}$ cell populations, HPCs and small CECs, were observed in sunitinib-treated RCC patients. The increase in CECs is likely caused by sunitinib targeting of immature tumor vessels.

Keywords Circulating endothelial (progenitor) cells . Renal cell cancer patients - Sunitinib - VEGF . Erythropoietin

\section{Introduction}

Anti-angiogenic compounds have shown efficacy in the clinic during recent years. In particular, the anti-vascular endothelial growth factor (VEGF) antibody bevacizumab [1] and the receptor tyrosine kinase inhibitors (TKIs) of the VEGF receptor family [2], sunitinib [3, 4] and sorafenib [5], have proven activity in a number of tumor types [6].

Sunitinib is an oral TKI of the VEGF receptors, plateletderived growth factor (PDGF) receptors, Flt-3 and c-Kit, and has been approved for treatment of advanced renal cell 
cancer (RCC) and imatinib-resistant gastrointestinal stromal tumors (GISTs). In a phase III trial in RCC patients, sunitinib has proven to be effective, albeit that a subset of RCC patients did not benefit from it [4]. Therefore, there is still a need for better understanding which conditions, factors, and cells facilitate or limit the beneficial effects of sunitinib on tumors.

In addition to immunohistochemical staining of tumor biopsies and imaging techniques that quantify tumor growth and perfusion [7], measurement of plasma circulating proteins, such as VEGF [8] or soluble VEGFRs [9], may reflect responsiveness to treatment. However, VEGF or sVEGFR2 plasma levels have not been shown to be predictive of response to sunitinib in GIST patients [10]. Alternatively, changes in the levels of circulating cells, such as newly recruited progenitor cells and monocytes or detached endothelial cells may be induced by anti-angiogenic treatment $[7,11]$.

Circulating endothelial progenitor (CEPs) cells have been suggested as potential pharmacodynamic or predictive biomarker in tumor patients [11]. CEPs were first described by Asahara et al. [12], who introduced the concept of circulating, bone marrow-derived endothelial progenitor cells, contributing to adult vasculogenesis. Later, Lyden et al. [13] have demonstrated that both VEGFR2 ${ }^{\text {pos }}$-circulating endothelial cells as well as VEGFR $1^{\text {pos }}$-myeloid, monocytic cells contributed to tumor vascularization. Recently, the source of highly proliferative endothelial outgrowth cells (EOCs) has been identified in CD $34^{\text {pos }} / \mathrm{CD} 45^{\text {neg }} / \mathrm{CD} 133^{\text {neg }}$ circulating cell populations [14, 15]. Besides CEPs, circulating endothelial cells (CECs) as thought to be shed from mature blood vessels may reflect the efficacy of anti-vascular treatment, as suggested in a number of studies [10, 16-18]. At present, no studies have reported on changes in frequencies of CECs or CEPs in combination with hematopoietic progenitor cells (HPCs) during sunitinib treatment of RCC patients.

Previously, we have identified a rare population of small CD $45^{\text {neg }} / \mathrm{CD} 34^{\text {bright }} / \mathrm{CD} 133^{\text {neg }} /$ VEGFR2 ${ }^{\text {pos }}$ cells in the peripheral blood (PB) of healthy volunteers, with increased numbers in cancer patients [19]. On the basis of endothelial marker expression these cells were indicated as "small-size EC-like cells" or CECs [20], because they are relatively small $(<10 \mu \mathrm{m})$ when compared with mature CECs [21-23]. Also, their marker profile is the same as that of the source of highly proliferative late outgrowth endothelial cells present in umbilical cord blood or PB [15] and is clearly distinct from $\mathrm{CD} 45^{\mathrm{dim}} / \mathrm{CD} 34^{\text {bright }} / \mathrm{CD} 133^{+}$hematopoietic progenitors. Here, we demonstrate that these CECs increase during sunitinib treatment of RCC patients in parallel to plasma VEGF and erythropoietin (EPO) levels, while HPCs and monocytes show the opposite changes, i.e., a decrease. In addition, a preliminary evaluation of the relation of CECs with clinical response is discussed.

\section{Patients and methods}

Patients and study design

From January 2006 to March 2007, 24 patients treated with sunitinib for advanced RCC in an expanded access program were included.

Sunitinib was administered orally, as monotherapy, at the currently recommended dose of $50 \mathrm{mg}$ daily in cycles of 6 weeks, consisting of 4 weeks on treatment followed by 2 weeks of rest ( $4 / 2$ schedule). Before study entry, each participant signed an institutional review board-approved protocol-specific informed consent in accordance with national and institutional guidelines, which strictly adhere to the principles of the Declaration of Helsinki and its subsequent amendments. During cycle 1, PB was taken on four occasions: C1D1 before receiving the first dose of sunitinib, C1D14, C1D28, and C2D1 (=C1D42) before administration of sunitinib of cycle 2. Computed tomography (CT) or magnetic resonance imaging (MRI) was performed before treatment and after every two to three cycles to assess clinical response according to response evaluation criteria in solid tumors (RECIST) [24]. RECIST is based on the sum of the largest diameters of appointed target tumor lesions at baseline and compared with the sum calculated in follow-up scans. Progression was defined based on $20 \%$ increase in the sum of the target lesions or clear clinical evidence of progressive disease (PD), and a $20 \%$ decrease in the sum of the target lesions was considered as partial response (PR). Responses not fitting these criteria were considered as stable disease (SD). Tumor response, PFS, and overall survival (OS) were used as parameters of treatment outcome. The PFS was the time between the first day of sunitinib and the date of PD on CT or MRI or clear clinical evidence of PD. OS was the time between the first day of treatment and the date of death or the date on which patients were last known to be alive. Data collection was closed on January 1st, 2008.

HPCs, CECs, and plasma monitoring

At the time of blood sampling, the first $2 \mathrm{ml}$ of blood was discarded and blood for flow cytometric enumerations was processed within 2-4 h. At each time-point, $7 \mathrm{ml}$ of EDTA blood and $7 \mathrm{ml}$ of citrate blood in a CPT tube (Becton Dickinson) were collected for measurement of circulating cell populations. One milliliter of full blood was used for the measurement of CECs and HPCs, based on CD45 and 
CD34 marker expression and expressed as number per milliliter, as published in detail [19]. Analysis of the subsets of cells was performed with the antibodies CD45FITC, CD34-APC, and IgG isotypes as has been described in detail [19]. For additional measurements of cell populations in patients, VEGFR2-APC and -PE antibodies were used. The viability marker 7-AAD was used to gate viable cells and annexin-V staining was used to determine early stages of apoptosis. To assure the gating of nucleated small CD34 ${ }^{\text {bright }}$ cells only, in a number of patients, we added extra analysis tubes using the dye styril-751 (LDS-751). Furthermore, we added tubes with 7 -AAD plus $0.1 \%$ saponin to permeabilize the cells and allow access of the dye to nuclei of viable cells as described before [19, 25]. Flow cytometry was performed on a FACSCalibur (BD Biosciences) and data were analyzed using CellQuest Pro software. Subfractions of white blood cells (WBC) were calculated as number per milliliter of blood by using standard total WBC count on Sysmex [19]. The remaining EDTA blood was used for the preparation of plasma and stored at $-80^{\circ} \mathrm{C}$. Plasma VEGF levels and EPO were measured in duplicate with enzyme-linked immunosorbent assay (ELISA) kits (R\&D Systems, Minneapolis). Albumin was determined using conventional methods in the department of clinical chemistry.

Human umbilical cord blood was obtained from fullterm deliveries and was processed for flow cytometry, according to the patients $\mathrm{PB}$ samples and used as a reference to identify the $\mathrm{CD} 45^{\text {neg }} / \mathrm{CD} 34^{\text {bright }} / \mathrm{CD} 133^{\text {neg }} \mathrm{CEC}$ population [15].

\section{Statistics}

Frequencies of circulating cell populations (numbers $/ \mathrm{ml}$ ), plasma levels of VEGF (pg/ml), and EPO (mIU/ml) were enumerated and expressed as median (range). Wilcoxon Signed Ranks test (SPSS for Windows 14.0, SPSS, Inc., Chicago, IL) was used to compare the biomarkers at pre-treatment and during treatment on C1D14, C1D28, and C2D1. Clinical benefit (CB) was defined as SD plus PR. PFS and OS were calculated with the KaplanMeier method and tested with the log rank test. Values of $P \leq 0.05$ (two-sided) were considered statistically significant.

\section{Results}

Patient characteristics and response to treatment

Twenty-four RCC patients treated with sunitinib were enrolled in the study. One patient died on C1D14, due to early progression and was excluded from the analysis. The remaining patients ( 17 males and 6 females) had a median age of 63 years (range 40-84) at the start of treatment. For further patients characteristics, see Tables 1 and 2 .

Two out of twenty-three patients could not be evaluated for treatment response because of early discontinuation due to sunitinib-related side-effects. Of the 21 evaluable

Table 1 Patient characteristics and best response to sunitinib treatment

\begin{tabular}{|c|c|c|}
\hline Characteristic & No. & $\%$ \\
\hline Total & 23 & 100 \\
\hline \multicolumn{3}{|l|}{ Sex } \\
\hline Male & 17 & 74 \\
\hline Female & 6 & 26 \\
\hline Median age, years (range) & $63(40-84)$ & \\
\hline \multicolumn{3}{|l|}{ Histology } \\
\hline Clear cell & 19 & 83 \\
\hline Papillary & 3 & 13 \\
\hline Other & 1 & 4 \\
\hline \multicolumn{3}{|l|}{ Prior treatment } \\
\hline Prior nephrectomy & 17 & 74 \\
\hline Prior cytokine-based therapy & 15 & 65 \\
\hline \multicolumn{3}{|l|}{ Site of metastatic disease } \\
\hline Lung & 20 & 87 \\
\hline Liver & 9 & 39 \\
\hline Bone & 4 & 17 \\
\hline \multicolumn{3}{|l|}{ No. of disease sites } \\
\hline 1 & 3 & 13 \\
\hline 2 & 5 & 22 \\
\hline$\geq 3$ & 15 & 65 \\
\hline \multicolumn{3}{|l|}{ MSKCC risk groups [53] } \\
\hline Favorable risk & 3 & 13 \\
\hline Intermediate risk & 15 & 65 \\
\hline Poor risk & 5 & 22 \\
\hline \multicolumn{3}{|c|}{ Best response to sunitinib treatment ${ }^{\mathrm{a}}$} \\
\hline Partial response & 4 & $17(19)$ \\
\hline Stable disease & 11 & $48(52)$ \\
\hline Progressive disease & 6 & $26(29)$ \\
\hline No evaluation ${ }^{\mathrm{b}}$ & 2 & $7(-)$ \\
\hline Progression-free survival $^{c}$ & $8.0(1.1-19.3)$ & - \\
\hline Survival $^{\mathrm{d}}$ & $12.7(1.4-23.2)$ & - \\
\hline
\end{tabular}

MSKCC, Memorial Sloan-Kettering Cancer Center

${ }^{a} \mathrm{CT}$ or MRI was performed before treatment and after every two to three cycles to assess clinical response according to response evaluation criteria in solid tumors (RECIST) [24]

b Two out of 23 patients could not be evaluated for treatment response because of early discontinuation due to sunitinib related side-effects

c The PFS was the time between the first day of sunitinib and the date of progressive disease (PD) on CT or MRI or clear clinical evidence of PD

d Survival was the time between the first day of treatment and the date of death or the date on which patients were last known to be alive 
Table 2 Patients characteristics and best response to sunitinib

\begin{tabular}{|c|c|c|c|c|c|c|c|}
\hline Patient no. & Age (years) & Sex & RCC type & Prior treatment & Response $^{\mathrm{a}}$ & PFS (months) & Survival (months) \\
\hline 1 & 68 & $\mathrm{~F}$ & Clear cell & Second-line & PR & 18.4 & 23.2 \\
\hline 2 & 48 & M & Clear cell & Second-line & PD & 3.0 & 8.2 \\
\hline 3 & 40 & M & Papillary ca & Second-line & SD & 10.1 & 11.0 \\
\hline 4 & 76 & M & Clear cell & Second-line & SD & 7.0 & 12.3 \\
\hline 5 & 57 & M & Clear cell & Second-line & SD & 10.6 & 22.2 \\
\hline 6 & 62 & $\mathrm{~F}$ & Clear cell & Second-line & PR & 5.8 & 20.7 \\
\hline 7 & 66 & M & Papillary ca & Second-line & PD & 1.2 & 1.4 \\
\hline 8 & 60 & M & Clear cell & Second-line & PR & 19.4 & 19.3 \\
\hline 9 & 81 & M & Clear cell & Second-line & SD & 11.0 & 11.2 \\
\hline 10 & 45 & M & Papillary ca & Second-line & PD & 2.6 & 4.6 \\
\hline 11 & 70 & M & Clear cell & First-line & SD & 8.4 & 9.1 \\
\hline 12 & 59 & M & Clear cell & First-line & SD & 9.3 & 15.5 \\
\hline 13 & 59 & M & Clear cell & First-line & PD & 2.6 & 10.9 \\
\hline 14 & 73 & $\mathrm{~F}$ & Clear cell & First-line & SD & 3.6 & 4.6 \\
\hline 15 & 74 & M & Clear cell & First-line & SD & 2.0 & 14.9 \\
\hline 16 & 59 & M & Clear cell & Second-line & PR & 8.9 & 12.7 \\
\hline 17 & 57 & $\mathrm{~F}$ & Clear cell & First-line & - & - & 9.7 \\
\hline 18 & 69 & $\mathrm{~F}$ & Clear cell & First-line & SD & 16.5 & 16.5 \\
\hline 19 & 84 & $\mathrm{~F}$ & Clear cell & Second-line & - & - & 16.6 \\
\hline 20 & 60 & M & Clear cell & Second-line & SD & 8.0 & 15.3 \\
\hline 21 & 57 & M & Clear cell & Second-line & PD & 2.3 & 13.8 \\
\hline 22 & 48 & M & Chromophobe ca & First-line & PD & 1.1 & 2.0 \\
\hline 23 & 64 & $\mathrm{M}$ & Clear cell & Second-line & SD & 5.1 & 9.0 \\
\hline
\end{tabular}

RCC, renal cell cancer; F, female; M, male; PR, partial response; SD, stable disease; PD, progressive disease; PFS, progression-free survival

${ }^{\text {a }}$ According to response evaluation criteria in solid tumors

patients, 4 patients (19\%) achieved a PR as best response, 11 patients $(52 \%)$ had SD, and 6 patients (29\%) had PD. The median PFS of these 23 patients was 8.0 months (range 1.1-19.3) and the median OS was 12.7 months (range 1.4-23.2).

Blood cell counts during the first cycle of sunitinib

The median WBC count of the patients showed a decrease from $7.9 \times 10^{6}$ to $6.9 \times 10^{6}$ cells $/ \mathrm{ml}$ on C1D14 $(n=23$; $P=0.002$ ) and a further decrease on C1D28 (from median pre-treatment $7.9 \times 10^{6}$ to $4.4 \times 10^{6}$ cells $/ \mathrm{ml}, n=15$; $P=0.001$ ), which partly reverted after 2 weeks of rest (from median pre-treatment $7.7 \times 10^{6}$ to $4.8 \times 10^{6}$, $n=15 ; \quad P=0.001)$. A similar pattern was seen for thrombocytes, neutrophils, and monocytes. The reduction of circulating monocytes and their partial recovery proceeded faster than the total WBC change, whereas the neutrophil decrease showed a more delayed effect. Erythrocytes and hemoglobin showed the reverse, i.e., a significant increase after 14 and 28 days, while the number of lymphocytes and basophils did not change during sunitinib treatment (Fig. 1).

Marker profile of two CD34 $4^{\text {bright }}$ populations: CECs and HPCs

Two populations of $\mathrm{CD} 34^{\text {bright }}$ circulating cells were evaluated, CECs and HPCs. The definitions of CECs and HPCs, according to CD45 and CD34 expression are visualized for a representative RCC patient (Fig. 2a) and for comparison from cord blood (Fig. 2b). CECs are CD45 $5^{\text {neg }}$ and $\mathrm{CD} 133^{\text {neg }}$; HPCs are $\mathrm{CD} 45^{\mathrm{dim}}$ and are largely $\mathrm{CD} 133^{\text {pos }}$ (Fig. 2a, b). Moreover, CECs have a slightly higher CD34 brightness than the majority of HPCs [19]. CECs are small in size being comparable with HPCs. CECs are viable cells, because they all exclude 7-AAD. We also checked in separate analysis tubes that both the $\mathrm{CD} 34^{\text {bright }}$ $\mathrm{CD} 45^{\text {neg }}$ and $\mathrm{CD} 34^{\text {bright }} \mathrm{CD} 45^{\mathrm{dim}}$ population had a similar positive 7-AAD/saponin staining as well as LDS-751 staining, confirming that both populations are nucleated cells. Other markers for which CECs are positive are 
Fig. 1 Blood cell count and hemoglobin during treatment with sunitinib. Median (range) values are shown. Timepoints of measurement: $C 1 D 1$, cycle 1 day $1(n=23)$; $C 1 D 14$, cycle 1 day $14(n=23)$; $C 1 D 28$, cycle 1 day $28(n=15) ; C 2 D 1$, cycle 2 day 1 before start of the second cycle $(n=15)$. Wilcoxon Signed rank test, * $P<0.01$, ** $P<0.05$
White Blood Cells (WBCs)
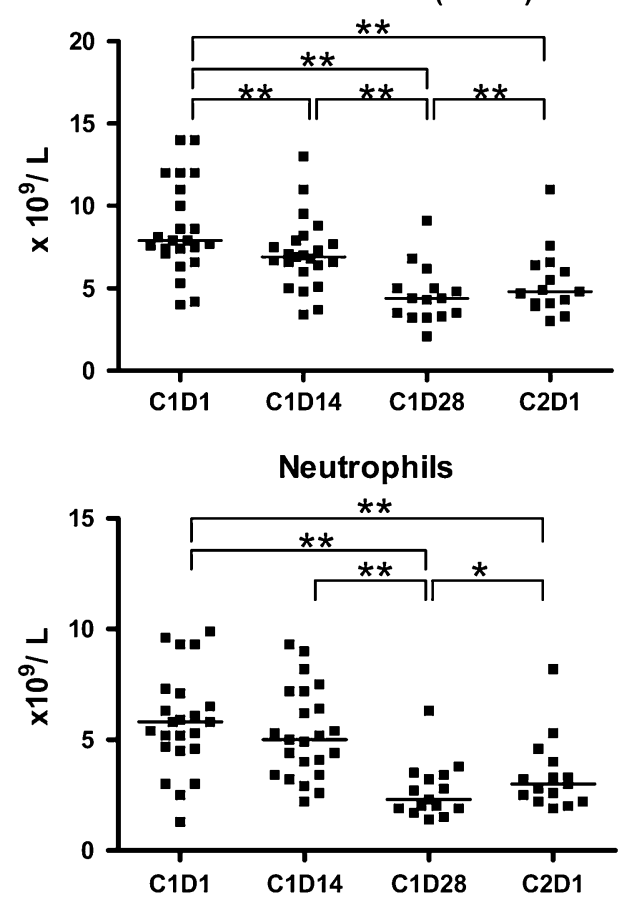

Monocytes
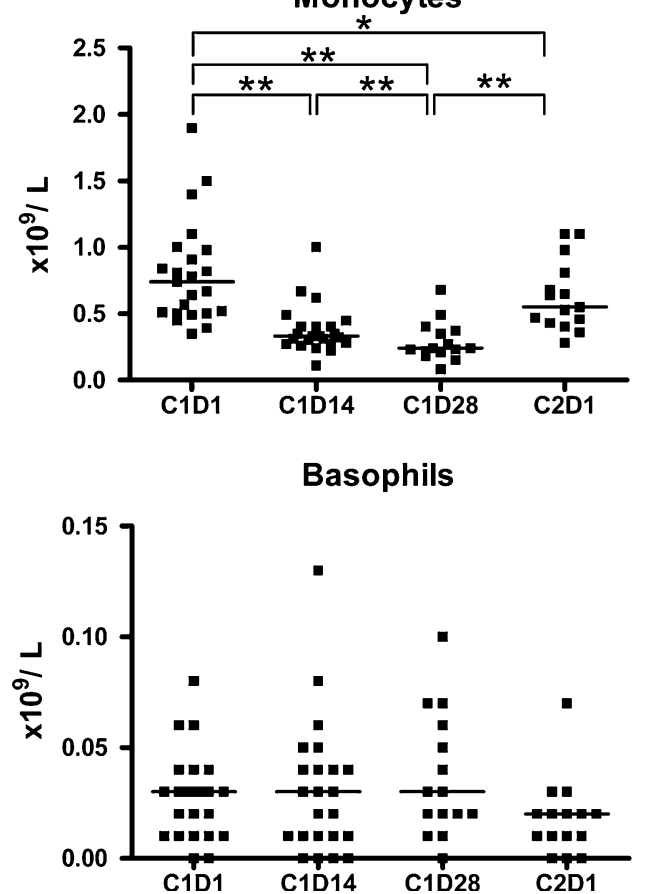

Lymphocytes

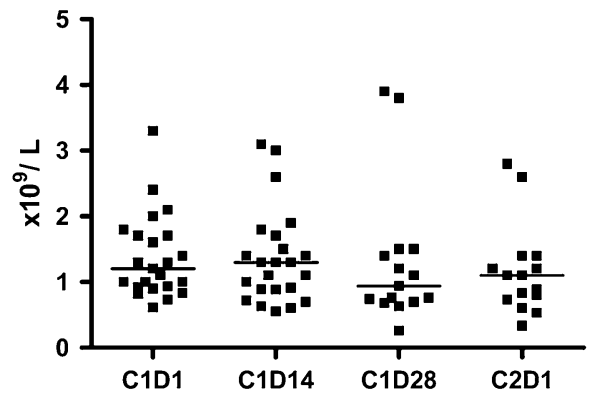

Erythrocytes

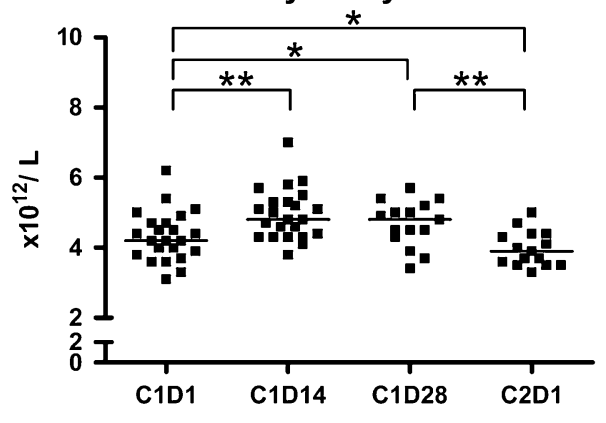

Hemoglobin

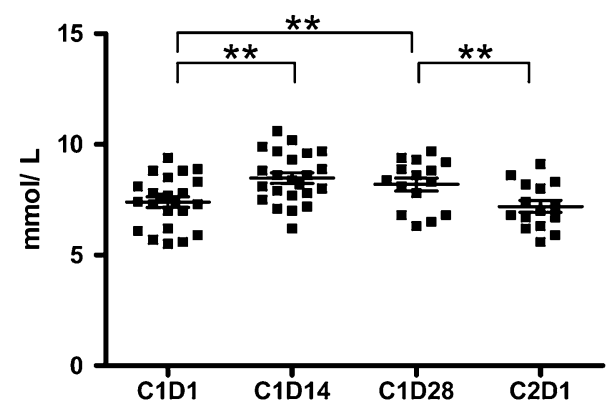

Thrombocytes

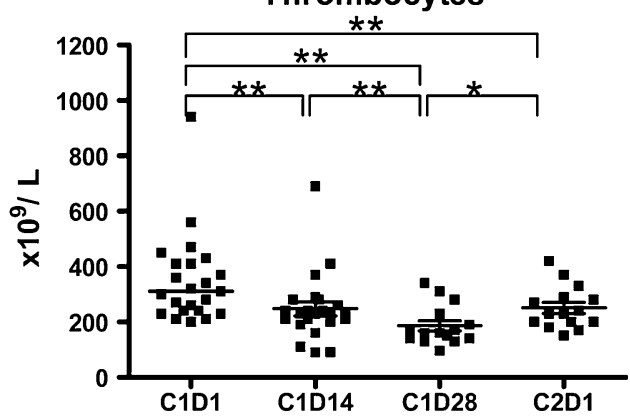

CD31, CD105, CD146, and VEGFR2, as previously reported [19]. To confirm the VEGFR2 expression on CECs, we have measured VEGFR2 in parallel, in additional cancer patients. VEGFR2 positivity in CECs was high (median $65 \%$ ), in contrast to the CD $45^{\text {dim }} / \mathrm{CD} 34^{\text {bright }}$ HPCs $(<1 \%)$. In addition, the EPO receptor was evaluated on CECs of five sunitinib-treated patients and was found present in $83.3 \%$ of the CECs (median range 66.7-93.3\%).
Plasma membrane VE-cadherin was undetectable in CECs in five treated patients (data not shown).

Kinetics of CECs and HPCs during the first cycle of sunitinib

A distinct difference in the kinetics of CECs (CD45 ${ }^{\text {neg }}$ / $\left.\mathrm{CD} 34^{\text {bright }} / 7-\mathrm{AAD}^{\text {neg }}\right)$ and HPCs (CD $45^{\text {dim }} / \mathrm{CD} 34^{\text {bright/ }}$ 

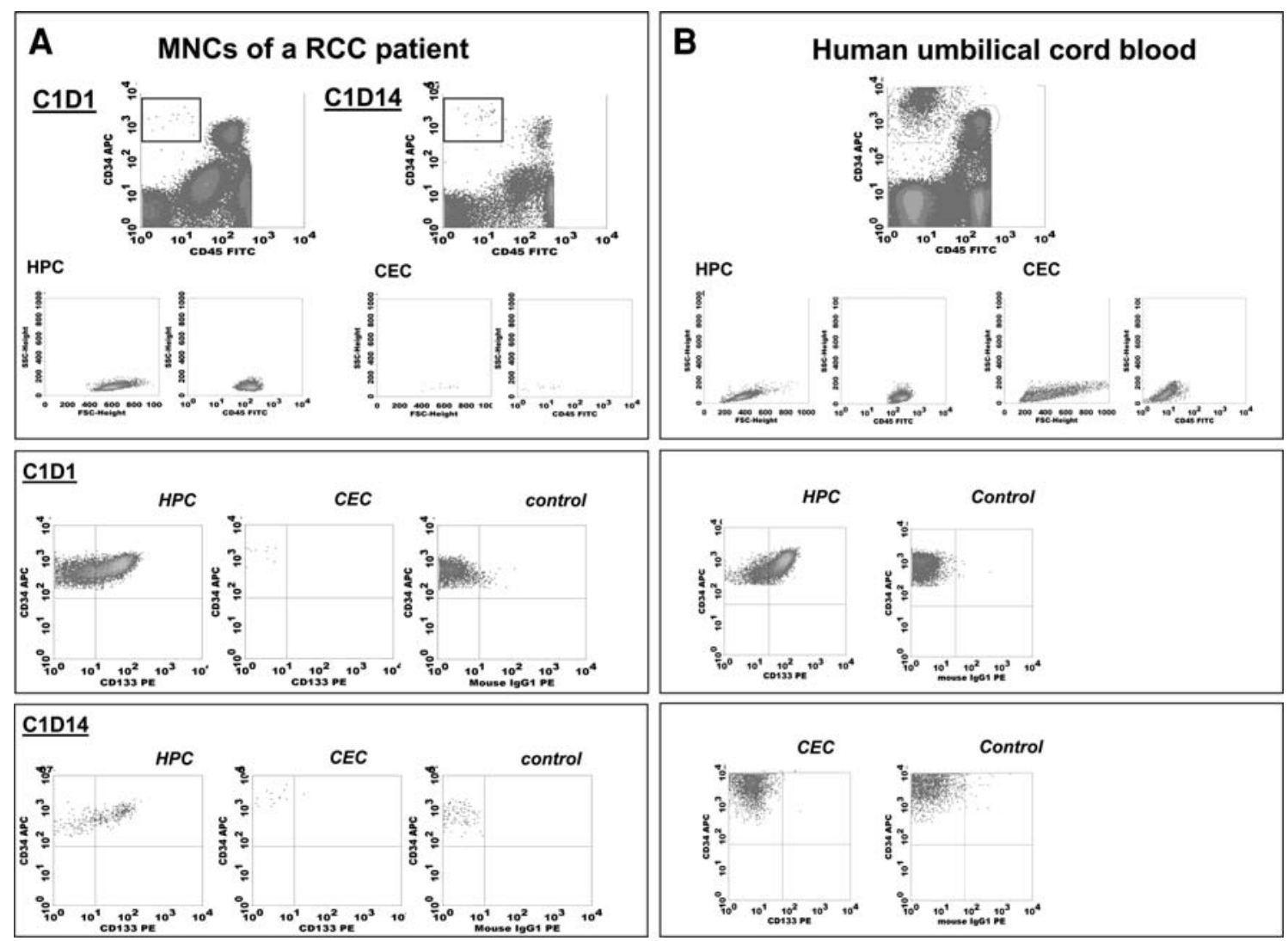

Fig. 2 Detection of hematopoietic progenitor cells (HPCs) and circulating endothelial cells (CECs) using four-color flow cytometry. The mononuclear(MNC)-fraction of a renal cell cancer (RCC) patient on C1D1 and C1D14 (a) and human umbilical cord blood (b). In the upper panel CD45, CD34 expression, size and granularity is shown

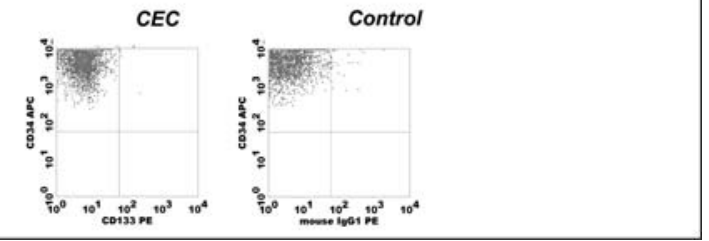

for HPCs and CECs. HPCs measured as CD45 dim $/ C D 34^{\text {bright }}$ and $C E C$ s measured as $C D 45^{\text {neg }} / C D 34^{\text {bright }}$ (see box). Second and third panel is showing CD133 expression for both HPCs and CECs when compared with the isotype control

7-AAD ${ }^{\text {neg }}$ ) was observed during the first cycle of sunitinib (Fig. 3a). The median number of viable CECs before treatment (C1D1) was 69 cells/ml (range 8-472), much lower than the number of HPCs $(1,350$ cells $/ \mathrm{ml}$, range 305-5,351). The median of CECs increased from 69 on C1D1 to 180 cells $/ \mathrm{ml}$ on C1D14 $(n=23 ; P=0.001)$ and from pre-treatment 76 to 229 cells $/ \mathrm{ml}(n=14 ; P=0.013)$ on C1D28, while the HPCs displayed an opposite kinetic pattern and decreased from 1,350 to 372 cells/ml on C1D14 ( $n=23 ; P<0.001)$ and from pre-treatment 1,567 to 409 cells $/ \mathrm{ml}$ on C1D28 $(n=14 ; P=0.001)$. Both cell populations returned to values close to the pre-treatment levels after the 2-week period of rest (C2D1; Fig. 3a). In a group of non-small cell lung cancer patients not treated with a VEGFR inhibitor, but treated with the EGF receptor inhibitor erlotinib, the CECs did not change significantly over a 3-week period (data not shown).

When the kinetic changes in circulating cells were expressed as percentage of pre-treatment values within individual patients, $102 \%$ increase in CECs numbers was observed after 2 weeks of treatment, whereas the HPCs showed a $65 \%$ decrease (Fig. 3b). A similar change was found on C1D28 $(n=14)$.

Plasma VEGF and EPO levels during the first cycle of sunitinib

Plasma levels of VEGF before treatment of sunitinib varied more than tenfold among individual patients and had a median value of $82 \mathrm{pg} / \mathrm{ml}$ (range 29-348, $n=19$ ). These median levels increased from 82 to $185 \mathrm{pg} / \mathrm{ml}$ on C1D14 $(n=19 ; P=0.001)$, from median pre-treatment 79 to $198 \mathrm{pg} / \mathrm{ml}$ on C1D28 ( $n=12 ; P=0.028)$ and returned to near pre-treatment levels on C2D1 (from 79 to $75 \mathrm{pg} / \mathrm{ml}$; $n=12, P=0.875$; Fig. $3 \mathrm{~b}$ ). In a subgroup of patients, we assessed EPO levels and the median plasma EPO level on C1D1 was $12 \mathrm{mIU} / \mathrm{ml}$, which increased with $63 \%$ after 14 days (median, $n=20$, Fig. 3c). In six patients, EPO was measured during the complete cycle (Fig. 3d) showing increases of 60 and $216 \%$ at days C1D14 and C1D28, respectively, which remained above baseline level at C2D1. Albumin concentrations determined in a larger group of 
Fig. 3 Circulating endothelial cells $(C E C s)$, total hematopoietic progenitor cells $(H P C s)$, erythropoietin $(E P O)$ levels, and changes of $V E G F$ levels in comparison with changes of blood cells during treatment with sunitinib. a Frequencies of CECs/ml and viable HPCs $/ \mathrm{ml}$ are shown before $(C 1 D 1, n=23)$, and on C1D14 $(n=23), C 1 D 28$

$(n=14)$, and $C 2 D 1(n=14)$ after start of sunitinib treatment. b Percentage change in circulating cells and plasma $V E G F$ levels on different timepoints during sunitinib treatment are given. $\mathbf{c}$ and d Plasma EPO levels are shown. In (a), (c), and (d) individual data and the median values are shown, while in Fig. 3b pretreatment levels $(C 1 D 1)$ were used as starting-point and percentage of change on C1D14 (and other timepoints) was calculated for each individual patient. Wilcoxon Signed rank test, $* P<0.01$, ** $P<0.05$, ns not significant
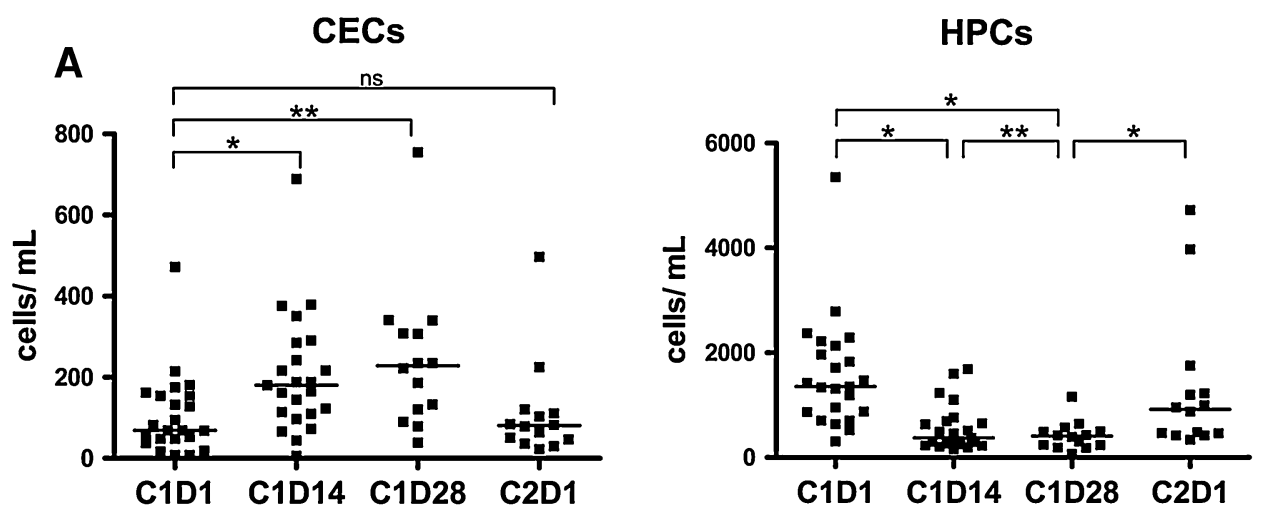

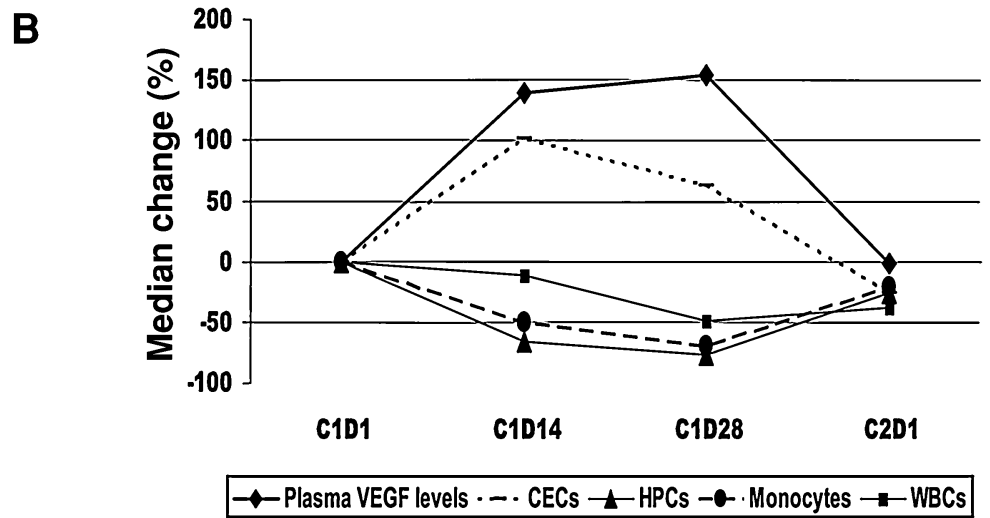

Plasma EPO levels

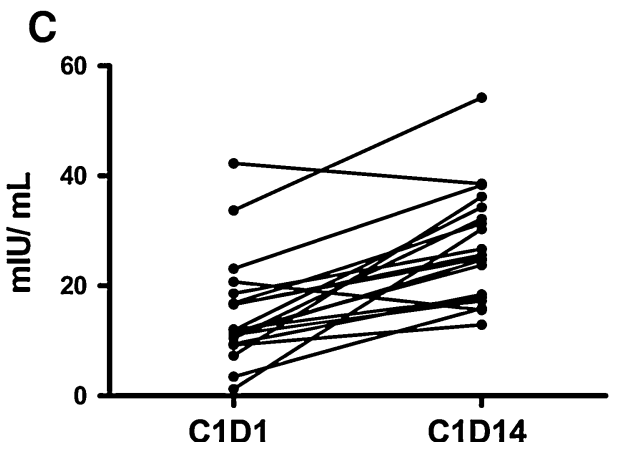

Plasma EPO levels

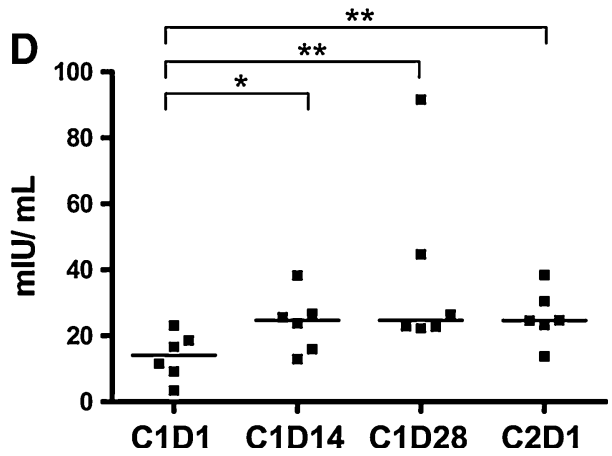

RCC patients treated with sunitinib were unaltered at C1D28 $(n=67)$ in comparison with the initial values at C1D0, $n=81$ (median of $38 \mu \mathrm{mol} / 1$ range $17-50 \mu \mathrm{mol} / \mathrm{l}$ and median of $41 \mu \mathrm{mol} / 1$ range $22-52 \mu \mathrm{mol} / 1$, respectively).

Biomarkers and treatment outcome

Clinical benefit was observed in 15 out of 21 RCC patients. Seventeen of all patients had clear cell RCC, of which 14 showed CB. PD was observed in 6 patients; 3 clear cell RCC patients, 2 papillary carcinoma, and 1 chromophobe carcinoma indicating that the patients with a clear cell carcinoma had a good response to sunitinib. In the CB group, the change in CECs after 14 days was increased in
14 out of 15 patients and in the PD group 4 out of 6 patients showed an increase, while 2 had a decrease. An increased number of CECs $(n=18)$ after 14 days of sunitinib treatment, was associated with a longer PFS when compared with patients $(n=3)$ with a decreased number of CECs (log rank test; $P=0.034$ ).

\section{Discussion}

We have investigated the changes in the frequency of circulating cells with specific emphasis on a population of small $\mathrm{CD} 45^{\text {neg }} / \mathrm{CD} 34^{\text {bright }} \mathrm{CECs}$, previously shown to be $\mathrm{CD} 31^{\mathrm{pos}} / \mathrm{CD} 105^{\mathrm{pos}} / \mathrm{CD} 146^{\mathrm{pos}} / \mathrm{VEGFR} 2^{\mathrm{pos}} / \mathrm{CD} 133^{\text {neg }}[19]$, 
in advanced RCC patients during the first cycle of sunitinib treatment. CECs increased in parallel to plasma VEGF and EPO levels during the 4-week on and decreased during the 2-week off sunitinib period, while monocytes and HPCs displayed an opposite pattern of change.

Blood cell-based biomarker analysis related to sunitinib activity and clinical outcome has been studied only in GIST patients with the main conclusion that a smaller decrease in monocyte levels was seen in patients with clinical benefit compared to those with PD [10]. We observed a decrease in circulating monocyte number after sunitinib treatment in RCC patients in agreement with the GIST study; a correlation with response was not seen in our population, possibly related to the limited number of patients with PD.

The number of HPCs decreased already maximally at C1D14 in our patient group, in parallel to the monocytes, while the overall WBC count dropped more slowly, due to a more delayed change in circulating neutrophils (Fig. 1). The decrease in HPCs might be partly related to bone marrow suppression associated with the Flt3-inhibitory action of sunitinib, since Flt3-signaling is required for HPC proliferation [26, 27].

Despite intense interest in developing biomarker tests for response prediction [7, 28, 29], levels of CECs during sunitinib treatment of RCC patients have not yet been reported. Therefore, the most interesting and novel finding of our study was the increase in CD45 $5^{\text {neg }} / \mathrm{CD} 34^{\text {bright }} \mathrm{CECs}$ during sunitinib treatment. The CEC population in $\mathrm{PB}$ is a rare cell population [20], which is increased two to threefold in cancer patients [19]. In the present patient group, the median pre-treatment (C1D1) frequency of the CECs was 69 cells $/ \mathrm{ml}(n=23)$, which is well-comparable to the median of 81 cells $/ \mathrm{ml}$ (range 32-132) in a mixed group of cancer patients [19]. The number of CECs approximately doubled in the RCC patient group by sunitinib treatment. Since we found a similar twofold increase in CEC levels (without decrease in HPC numbers) in a group of bevacizumab plus erlotinib, but not erlotinib-single agent treated NSCLC patients (L. Vroling et al., unpublished) [30], this increase is more likely related to inhibition of VEGFR signaling by sunitinib, rather than to inhibition of other targets or off-target effects of sunitinib. Being a most likely specific target-related effect of sunitinib, this increase in CECs remains an interesting cell population to be further investigated.

An important question regards the precise nature and function of the CEC population that is elevated after sunitinib treatment, in particular in the light of the current controversies on the identification and role in tumor angiogenesis of CECs or CEPs [11, 14, 25, 31]. A plausible explanation for the increased number of CECs is that they reflect endothelial cells, which became detached or shed from sunitinib-targeted immature (tumor) blood vessels. Although we have defined this population by the marker combination of $\mathrm{CD} 45^{\text {neg }}$ and $\mathrm{CD} 34^{\text {bright }}$, which are both essential for discriminating these cells from the HPCs and all other MNCs, in theory, it may still be heterogeneous with regard to other EC markers. Importantly, we have assessed that this population has the highest VEGFR2 positivity (median $65 \%$ ) of all by us defined cell populations in the $\mathrm{PB}$, further supporting their endothelial nature. CECs are commonly characterized and defined by a heterogeneous, but rather large size and granularity, exceeding that of most mononuclear cell populations, typically $>20 \mu \mathrm{m}$ [22, 32, 33] and a high CD146 expression allowing selective extraction with immunobeads [34]. The median diameter of $\mathrm{CD} 146^{+}$PBMCs has been estimated $6.8 \mu \mathrm{m}$ versus that of $\mathrm{CD} 146^{+} \mathrm{CECs}$ as $21.5 \mu \mathrm{m}$ [22]. Our CECs are in the FSC/SSC range of the HPCs, which are $<10 \mu \mathrm{m}$. This fits with the idea that these small CECs originate from a rather immature vasculature and/or are mobilized bone marrow or vascular wall resident EPCs. In support of this explanation, several data suggest that sunitinib might selectively prune immature nascent tumor neovessels not yet adequately stabilized by pericyte coverage [35, 36], while relatively saving mature vessels leading to vessel normalization [37].

A characteristic of endothelial cells in vitro is that they rapidly become apoptotic after detachment from their matrix [38]. However, in studies that measure CEC frequencies in $\mathrm{PB}$, cell viability was either not assessed or the viability marker dye 7-AAD has been used to exclude dead cells, as in most flow cytometric approaches. While our CEC values are intact, CECs by the definition of exclusion of 7-AAD, more sensitive markers, such as annexin- $\mathrm{V}$ staining or the dye SYTO-16, can detect early stages of apoptosis in cells that still exclude 7-AAD [39]. We are not aware of studies reporting apoptotic CECs using annexin- $\mathrm{V}$ labeling, probably because this technique is not readily incorporated in most CEC protocols and also the use of frozen-thawed samples as used by some [10] precludes the reliable assessment of apoptotic cells [39]. Therefore, we have assessed the percentage of apoptotic CECs with annexin- $\mathrm{V}$ (with ammonium chloride) protocol in several RCC patients, separately from the main study protocol and found that the number of early apoptotic CECs was considerable (range $50-80 \%$ of CECs).

It should be noted that the endothelial cell marker VEcadherin was virtually absent in most of our CEC subpopulations, while others reported it to be present on mature CECs circulating in PB [40]. The lack of overt surface VE-cadherin expression may reflect the immature nature of these small CECs, or might also be explained by internalization during or after loss of endothelial junctions and detachment of the cells [41, 42]. 
An alternative possibility may be that our $\mathrm{CD} 45^{\text {neg/ }}$ CD34 ${ }^{\text {bright }}$ CECs have endothelial progenitor (CEP) characteristics, such as those recently ascribed to CD45 ${ }^{\text {neg/ }}$ CD $34^{\text {bright }} / \mathrm{CD} 133^{\text {neg }}$ cells $[14,15,43,44]$. A disturbed homing of VEGFR positive CEPs into the tumor vasculature caused by sunitinib might also contribute to the increase in $\mathrm{CD} 45^{\text {neg }} / \mathrm{CD} 34^{\text {bright }} \mathrm{CEC}$ population. It is important to note that the presence of a fraction of early apoptotic cells in the population of CECs does not exclude a priory the presence of endothelial progenitor cells, capable of highly proliferative outgrowth, since the $\mathrm{CD} 34^{\text {bright }} / \mathrm{CD} 45^{\text {neg }} / \mathrm{CD} 133^{\text {neg }}$ cell population from cord blood, which is the source of late EOCs, also contained up to $60 \%$ apoptotic cells (F. Timmermans, personal communication). This lends support to the idea that the EPCs or EOC precursors circulating in human PB might be in majority rather resident cells from peripheral sites than from the bone marrow [45] and might exist in multiple states of differentiation [46].

In addition to the increase in CECs, the soluble growth factor VEGF increased during sunitinib exposure and partly normalized 2 weeks after cessation of drug intake. This finding is in accordance with previous findings on VEGF receptor inhibition studies in mice and man $[10,47,48]$. The mechanism for the VEGF increase is not known, but according to the study of Ebos et al. [49], may reflect a direct or indirect physiological response to receptor inhibition by sunitinib. Indeed, we found also a prominent increase in EPO during the first cycle of sunitinib, consistent with the findings of Ebos et al. [49] in sunitinib-treated mice. Functional consequences of increased plasma EPO levels in sunitinibtreated patients remain to be defined.

The rapid return of VEGF and CECs to the pre-treatment levels during the 2-weeks rest period is remarkable. Studies by McDonald et al. [50] have pointed to the rapid repopulation of vascular casts after cessation of antiangiogenic treatment of tumor-bearing animals. The occurrence of a similar rapid resumption of vessel repair in the RCC patients might contribute to the rapid normalization of VEGF during the drug-free period.

The primary goal of this study was to investigate the presence and pattern of change of $\mathrm{CD} 34^{\text {bright }} / \mathrm{CD} 45^{\text {neg }}$ CECs, separated from $\mathrm{CD} 34^{\text {bright }} / \mathrm{CD} 45^{\text {pos }} \mathrm{HPCs}$ in a cohort of sunitinib-treated RCC patients. The question, whether the observed changes in CECs or other circulating subsets of cells are just a pharmacodynamic marker of sunitinib activity or might have a predictive value, needs to be addressed in a larger cohort of patients [51, 52].

In conclusion, this study shows that $\mathrm{CD} 34^{\text {bright }} \mathrm{CECs}$ and $\mathrm{CD} 34^{\text {bright }}$ HPCs counts change in opposite directions by sunitinib; monocytes and HPC decrease and CECs increase. $\mathrm{CD} 34^{\text {bright }} / \mathrm{CD} 133^{\text {neg }} \mathrm{CECs}$ might be detached ECs and reflect sunitinib anti-vascular effects or might include CEPs, which are potential targets.
Acknowledgments We thank Corinne N. Tillier and Henk A. Mallo for their help with patient care. Grant support: Supported by the European Union (FP6) Integrated project "Angiotargeting" (contract no. 504743). This study has been partly presented at the 99th AACR Annual Meeting in San Diego, April 2008.

Open Access This article is distributed under the terms of the Creative Commons Attribution Noncommercial License which permits any noncommercial use, distribution, and reproduction in any medium, provided the original author(s) and source are credited.

\section{References}

1. Hurwitz H, Fehrenbacher L, Novotny W et al (2004) Bevacizumab plus irinotecan, fluorouracil, and leucovorin for metastatic colorectal cancer. N Engl J Med 350:2335-2342. doi: 10.1056/NEJMoa032691

2. Choueiri TK, Rini B, Garcia JA et al (2007) Prognostic factors associated with long-term survival in previously untreated metastatic renal cell carcinoma. Ann Oncol 18:249-255. doi:10.1093/ annonc/mdl371

3. Demetri GD, van Oosterom AT, Garrett CR et al (2006) Efficacy and safety of sunitinib in patients with advanced gastrointestinal stromal tumour after failure of imatinib: a randomised controlled trial. Lancet 368:1329-1338. doi:10.1016/S0140-6736(06)694 46-4

4. Motzer RJ, Hutson TE, Tomczak P et al (2007) Sunitinib versus interferon alfa in metastatic renal-cell carcinoma. N Engl J Med 356:115-124. doi:10.1056/NEJMoa065044

5. Escudier B, Eisen T, Stadler WM et al (2007) Sorafenib in advanced clear-cell renal-cell carcinoma. N Engl J Med 356: 125-134. doi:10.1056/NEJMoa060655

6. Choueiri TK, Plantade A, Elson P et al (2008) Efficacy of sunitinib and sorafenib in metastatic papillary and chromophobe renal cell carcinoma. J Clin Oncol 26:127-131. doi:10.1200/JCO.2007. 13.3223

7. Jain RK, Duda DG, Clark JW, Loeffler JS (2006) Lessons from phase III clinical trials on anti-VEGF therapy for cancer. Nat Clin Pract Oncol 3:24-40. doi:10.1038/ncponc0403

8. Drevs J, Zirrgiebel U, Schmidt-Gersbach CI et al (2005) Soluble markers for the assessment of biological activity with PTK787/ZK 222584 (PTK/ZK), a vascular endothelial growth factor receptor (VEGFR) tyrosine kinase inhibitor in patients with advanced colorectal cancer from two phase I trials. Ann Oncol 16: 558-565. doi:10.1093/annonc/mdi118

9. Bocci G, Man S, Green SK et al (2004) Increased plasma vascular endothelial growth factor (VEGF) as a surrogate marker for optimal therapeutic dosing of VEGF receptor-2 monoclonal antibodies. Cancer Res 64:6616-6625. doi:10.1158/0008-5472. CAN-04-0401

10. Norden-Zfoni A, Desai J, Manola J et al (2007) Blood-based biomarkers of SU11248 activity and clinical outcome in patients with metastatic imatinib-resistant gastrointestinal stromal tumor. Clin Cancer Res 13:2643-2650. doi:10.1158/1078-0432.CCR06-0919

11. Le Tourneau C, Vidal L, Siu LL (2008) Progress and challenges in the identification of biomarkers for EGFR and VEGFR targeting anticancer agents. Drug Resist Updat 11:99-109. doi: 10.1016/j.drup.2008.04.001

12. Asahara T, Masuda H, Takahashi $\mathrm{T}$ et al (1999) Bone marrow origin of endothelial progenitor cells responsible for postnatal vasculogenesis in physiological and pathological neovascularization. Circ Res 85:221-228 
13. Lyden D, Hattori K, Dias S et al (2001) Impaired recruitment of bone-marrow-derived endothelial and hematopoietic precursor cells blocks tumor angiogenesis and growth. Nat Med 7:11941201. doi:10.1038/nm1101-1194

14. Hirschi KK, Ingram DA, Yoder MC (2008) Assessing identity, phenotype, and fate of endothelial progenitor cells. Arterioscler Thromb Vasc Biol 28:1584-1595. doi:10.1161/ATVBAHA.107. 155960

15. Timmermans F, Van Hauwermeiren F, De Smedt M et al (2007) Endothelial outgrowth cells are not derived from CD133+ cells or CD45+ hematopoietic precursors. Arterioscler Thromb Vasc Biol 27:1572-1579. doi:10.1161/ATVBAHA.107.144972

16. Batchelor TT, Sorensen AG, di Tomaso E et al (2007) AZD2171, a pan-VEGF receptor tyrosine kinase inhibitor, normalizes tumor vasculature and alleviates edema in glioblastoma patients. Cancer Cell 11:83-95. doi:10.1016/j.ccr.2006.11.021

17. Duda DG, Cohen KS, di Tomaso E et al (2006) Differential CD146 expression on circulating versus tissue endothelial cells in rectal cancer patients: implications for circulating endothelial and progenitor cells as biomarkers for antiangiogenic therapy. J Clin Oncol 24:1449-1453. doi:10.1200/JCO.2005.04.2861

18. Willett CG, Boucher Y, di Tomaso E et al (2004) Direct evidence that the VEGF-specific antibody bevacizumab has antivascular effects in human rectal cancer. Nat Med 10:145-147. doi:10.1038/ nm988

19. Vroling L, Yuana Y, Schuurhuis GJ et al (2007) VEGFR2 expressing circulating (progenitor) cell populations in volunteers and cancer patients. Thromb Haemost 98:440-450

20. Delorme B, Basire A, Gentile C et al (2005) Presence of endothelial progenitor cells, distinct from mature endothelial cells, within human CD146+ blood cells. Thromb Haemost 94: 1270-1279

21. Blann AD, Woywodt A, Bertolini F et al (2005) Circulating endothelial cells. Biomarker of vascular disease. Thromb Haemost 93:228-235

22. Clarke LA, Shah V, Arrigoni F et al (2008) Quantitative detection of circulating endothelial cells in vasculitis: comparison of flow cytometry and immunomagnetic bead extraction. $\mathrm{J}$ Thromb Haemost 6:1025-1032. doi:10.1111/j.1538-7836.2008.02953.x

23. Wu H, Chen H, Hu PC (2007) Circulating endothelial cells and endothelial progenitors as surrogate biomarkers in vascular dysfunction. Clin Lab (Zaragoza) 53:285-295

24. Therasse P, Arbuck SG, Eisenhauer EA et al (2000) New guidelines to evaluate the response to treatment in solid tumors. European Organization for Research and Treatment of Cancer, National Cancer Institute of the United States, National Cancer Institute of Canada. J Natl Cancer Inst 92:205-216. doi:10.1093/ jnci/92.3.205

25. Strijbos MH, Kraan J, den Bakker MA et al (2007) Cells meeting our immunophenotypic criteria of endothelial cells are large platelets. Cytometry B Clin Cytom 72:86-93. doi:10.1002/cyto.b. 20156

26. Faivre S, Demetri G, Sargent W, Raymond E (2007) Molecular basis for sunitinib efficacy and future clinical development. Nat Rev Drug Discov 6:734-745. doi:10.1038/nrd2380

27. Gabbianelli M, Pelosi E, Montesoro E et al (1995) Multi-level effects of flt3 ligand on human hematopoiesis: expansion of putative stem cells and proliferation of granulomonocytic progenitors/monocytic precursors. Blood 86:1661-1670

28. Broxterman HJ, Georgopapadakou NH (2007) Anticancer therapeutics: a surge of new developments increasingly target tumor and stroma. Drug Resist Updat 10:182-193. doi:10.1016/j.drup. 2007.07.001

29. Shaked Y, Ciarrocchi A, Franco M et al (2006) Therapy-induced acute recruitment of circulating endothelial progenitor cells to tumors. Science 313:1785-1787. doi:10.1126/science.1127592
30. Vroling L, van der Veldt AM, de Haas RR et al (2008) CD34bright/CD133neg candidate circulating endothelial progenitor cells (ccEPCs) are a potential biomarker during treatment with sunitinib or bevacizumab. AACR Meeting Abstracts. 2008: 4956

31. Purhonen S, Palm J, Rossi D et al (2008) Bone marrow-derived circulating endothelial precursors do not contribute to vascular endothelium and are not needed for tumor growth. Proc Natl Acad Sci USA 105:6620-6625. doi:10.1073/pnas.0710516105

32. Goon PK, Boos CJ, Lip GY (2005) Circulating endothelial cells: markers of vascular dysfunction. Clin Lab (Zaragoza) 51:531-538

33. Woywodt A, Blann AD, Kirsch $\mathrm{T}$ et al (2006) Isolation and enumeration of circulating endothelial cells by immunomagnetic isolation: proposal of a definition and a consensus protocol. $\mathrm{J}$ Thromb Haemost 4:671-677. doi:10.1111/j.1538-7836.2006. 01794.x

34. Widemann A, Sabatier F, Arnaud L et al (2008) CD146-based immunomagnetic enrichment followed by multiparameter flow cytometry: a new approach to counting circulating endothelial cells. J Thromb Haemost 6:869-876. doi:10.1111/j.1538-7836. 2008.02931.x

35. Palmowski M, Huppert J, Hauff P et al (2008) Vessel fractions in tumor xenografts depicted by flow- or contrast-sensitive threedimensional high-frequency Doppler ultrasound respond differently to antiangiogenic treatment. Cancer Res 68:7042-7049. doi: 10.1158/0008-5472.CAN-08-0285

36. Zhou Q, Guo P, Gallo JM (2008) Impact of angiogenesis inhibition by sunitinib on tumor distribution of temozolomide. Clin Cancer Res 14:1540-1549. doi:10.1158/1078-0432.CCR-07-4544

37. Jain RK (2005) Normalization of tumor vasculature: an emerging concept in antiangiogenic therapy. Science 307:58-62. doi:10.1126/ science. 1104819

38. Re F, Zanetti A, Sironi M et al (1994) Inhibition of anchoragedependent cell spreading triggers apoptosis in cultured human endothelial cells. J Cell Biol 127:537-546. doi:10.1083/jcb.127.2.537

39. Schuurhuis GJ, Muijen MM, Oberink JW et al (2001) Large populations of non-clonogenic early apoptotic CD34-positive cells are present in frozen-thawed peripheral blood stem cell transplants. Bone Marrow Transplant 27:487-498. doi:10.1038/ sj.bmt. 1702809

40. Jacques N, Vimond N, Conforti R et al (2008) Quantification of circulating mature endothelial cells using a whole blood fourcolor flow cytometric assay. J Immunol Methods 337:132-143. doi:10.1016/j.jim.2008.07.006

41. Gavard J, Gutkind JS (2006) VEGF controls endothelial-cell permeability by promoting the beta-arrestin-dependent endocytosis of VE-cadherin. Nat Cell Biol 8:1223-1234. doi:10.1038/ ncb1486

42. Xiao K, Garner J, Buckley KM et al (2005) p120-Catenin regulates clathrin-dependent endocytosis of VE-cadherin. Mol Biol Cell 16:5141-5151. doi:10.1091/mbc.E05-05-0440

43. Case J, Mead LE, Bessler WK et al (2007) Human CD34(+) AC133(+)VEGFR-2(+) cells are not endothelial progenitor cells but distinct, primitive hematopoietic progenitors. Exp Hematol 35:1109-1118. doi:10.1016/j.exphem.2007.04.002

44. Timmermans F, Plum J, Yoder MC et al (2009) Endothelial progenitor cells: identity defined? J Cell Mol Med 13:87-102. doi:10.1111/j.1582-4934.2008.00598.x

45. Aicher A, Rentsch M, Sasaki K et al (2007) Nonbone marrowderived circulating progenitor cells contribute to postnatal neovascularization following tissue ischemia. Circ Res 100:581-589. doi:10.1161/01.RES.0000259562.63718.35

46. Barber CL, Iruela-Arispe ML (2006) The ever-elusive endothelial progenitor cell: identities, functions and clinical implications. Pediatr Res 59:26R-32R. doi:10.1203/01.pdr.0000203553.464 71.18 
47. DePrimo SE, Bello CL, Smeraglia J et al (2007) Circulating protein biomarkers of pharmacodynamic activity of sunitinib in patients with metastatic renal cell carcinoma: modulation of VEGF and VEGF-related proteins. J Transl Med 5:32. doi:10.1186/14795876-5-32

48. Motzer RJ, Michaelson MD, Redman BG et al (2006) Activity of SU11248, a multitargeted inhibitor of vascular endothelial growth factor receptor and platelet-derived growth factor receptor, in patients with metastatic renal cell carcinoma. J Clin Oncol 24:16-24. doi:10.1200/JCO.2005.02.2574

49. Ebos JM, Lee CR, Christensen JG, Mutsaers AJ, Kerbel RS (2007) Multiple circulating proangiogenic factors induced by sunitinib malate are tumor-independent and correlate with antitumor efficacy. Proc Natl Acad Sci USA 104:17069-17074. doi:10.1073/ pnas.0708148104

50. Mancuso MR, Davis R, Norberg SM et al (2006) Rapid vascular regrowth in tumors after reversal of VEGF inhibition. J Clin Invest 116:2610-2621. doi:10.1172/JCI24612
51. Shojaei F, Ferrara N (2008) Role of the microenvironment in tumor growth and in refractoriness/resistance to anti-angiogenic therapies. Drug Resist Updat 11:219-230. doi:10.1016/j.drup. 2008.09.001

52. van Cruijsen H, van der Veldt AM, Vroling L et al (2008) Sunitinib-induced myeloid lineage redistribution in renal cell cancer patients: CD1c+ dendritic cell frequency predicts progressionfree survival. Clin Cancer Res 14:5884-5892. doi:10.1158/10780432.CCR-08-0656

53. Motzer RJ, Bacik J, Murphy BA, Russo P, Mazumdar M (2002) Interferon-alfa as a comparative treatment for clinical trials of new therapies against advanced renal cell carcinoma. J Clin Oncol 20:289-296. doi:10.1200/JCO.20.1.289 